\title{
The nicotinic acetylcholine receptor gene family of the honey bee, Apis mellifera
}

\author{
Andrew K. Jones, ${ }^{1}$ Valerie Raymond-Delpech, ${ }^{2}$ Steeve H. Thany, ${ }^{2}$ Monique Gauthier, ${ }^{2}$ \\ and David B. Sattelle $e^{1,3}$
${ }^{1}$ MRC Functional Genetics Unit, Department of Physiology Anatomy and Genetics, University of Oxford, Oxford OX1 3QX, United Kingdom; ${ }^{2}$ Centre de Recherches sur la Cognition Animale, Centre National de la Recherche Scientifique, \\ Unité Mixte de Recherche 5169, Université Paul Sabatier, 31062 Toulouse, France
}

\begin{abstract}
Nicotinic acetylcholine receptors ( $\mathrm{nAChRs)} \mathrm{mediate} \mathrm{fast} \mathrm{cholinergic} \mathrm{synaptic} \mathrm{transmission} \mathrm{and} \mathrm{play} \mathrm{roles} \mathrm{in} \mathrm{many}$ cognitive processes. They are under intense research as potential targets of drugs used to treat neurodegenerative diseases and neurological disorders such as Alzheimer's disease and schizophrenia. Invertebrate nAChRs are targets of anthelmintics as well as a major group of insecticides, the neonicotinoids. The honey bee, Apis mellifera, is one of the most beneficial insects worldwide, playing an important role in crop pollination, and is also a valuable model system for studies on social interaction, sensory processing, learning, and memory. We have used the A. mellifera genome information to characterize the complete honey bee $\mathrm{nAChR}$ gene family. Comparison with the fruit fly Drosophila melanogaster and the malaria mosquito Anopheles gambiae shows that the honey bee possesses the largest family of insect nAChR subunits to date (11 members). As with Drosophila and Anopheles, alternative splicing of conserved exons increases receptor diversity. Also, we show that in one honey bee nAChR subunit, six adenosine residues are targeted for RNA A-to-I editing, two of which are evolutionarily conserved in Drosophila melanogaster and Heliothis virescens orthologs, and that the extent of editing increases as the honey bee lifecycle progresses, serving to maximize receptor diversity at the adult stage. These findings on Apis mellifera enhance our understanding of $n A C h R$ functional genomics and provide a useful basis for the development of improved insecticides that spare a major beneficial insect species.
\end{abstract}

[Supplemental material is available online at www.genome.org. Sequence data from this article have been deposited with the EMBL/GenBank Data Libraries under accession nos. DQ026031-DQ026039.]

The honey bee, Apis mellifera, is an important beneficial insect in agriculture. In addition to producing honey and beeswax, the contribution of $A$. mellifera to crop pollination is valued at more than $\$ 14$ billion dollars per year in the U.S. alone (United States Department of Agriculture http://www.ars.usda.gov/main/ main.htm). Honey bees live in societies of considerable complexity and thus are studied as models for social behavior (Robinson et al. 1997).

The neonicotinoids are the newest major group of insecticides, which includes acetamiprid, clothianidin, dinotefuran, imidacloprid, nitenpyram, thiacloprid, and thiamethoxam (Tomizawa and Casida 2005). The worldwide annual sales of neonicotinoids amounts to $\sim 1$ billion dollars, and they are used against piercing-sucking pests (aphids, leafhoppers, and whiteflies) of major crops. In France, the use of imidacloprid has been suspended over concerns that it may be having a drastic effect on bee populations (http://www.pan-uk.org/press/pr140604.htm), highlighting the importance that effective insecticides should also show selectivity within insects so that pollinators such as $A$. mellifera are spared. While the link between imidacloprid use and bee population decline has yet to be proven, studies have shown that imidacloprid is highly toxic to A. mellifera (Suchail et al. 2004) and at sublethal doses can alter honey bee foraging and learning (Guez et al. 2001; Lambin et al. 2001; Decourtye et al.

\section{${ }^{3}$ Corresponding author.}

E-mail david.sattelle@anat.ox.ac.uk; fax 44-1865-282-651.

Article published online before print. Article and publication date are at http:// www.genome.org/cgi/doi/10.1101/gr.4549206. Freely available online through the Genome Research Open Access option.
2004). Neonicotinoids act as agonists on their molecular targets, nicotinic acetylcholine receptors (nAChRs) (Matsuda et al. 2001), which are prototypical members of the cys-loop ligand-gated ion channel (LGIC) superfamily (Karlin 2002). The fast actions of acetylcholine (ACh) at synapses are mediated by nAChRs, which consist of five homologous subunits arranged around a central ion channel (Corringer et al. 2000; Unwin 2005). Analyses of completed genomes have revealed diverse nAChR gene families with mammals possessing 16 subunit genes, chicken, 17 (Millar 2003), Fugu rubripes, 28 (Jones et al. 2003), and Caenorhabditis elegans, at least 27 (Jones and Sattelle 2004). In contrast, Drosophila melanogaster and Anopheles gambiae have notably smaller $\mathrm{nAChR}$ gene families, each consisting of 10 subunits (Jones et al. 2005; Sattelle et al. 2005).

To date, four A. mellifera nAChR subunits (Apis $\alpha 2$, Apis $\alpha 3$, Apis $\alpha$ 7-1, and Apis $\alpha$ 7-2) have been identified (Thany et al. 2003, 2005), which are expressed in brain structures that play roles in learning and memory, olfactory signal processing, mechanosensory antennal input, and visual processing. These findings are consistent with ACh being a major excitatory neurotransmitter in the insect nervous system (Breer and Sattelle 1987; Lee and O'Dowd 1999). Patch clamp studies have demonstrated the existence of a distinct nAChR subtype in the honey bee nervous system that is blocked by the nAChR antagonists $\alpha$-bungarotoxin $(\alpha-B t x)$, dihydroxy- $\beta$-erythroidine and methyllycaconitine, while nicotine and imidacloprid acted as partial agonists on this receptor (Goldberg et al. 1999; Déglise et al. 2002; Wustenberg and Grunewald 2004). Another study has shown the presence of two $\mathrm{nAChR}$ populations that differ in their responses to imidacloprid 


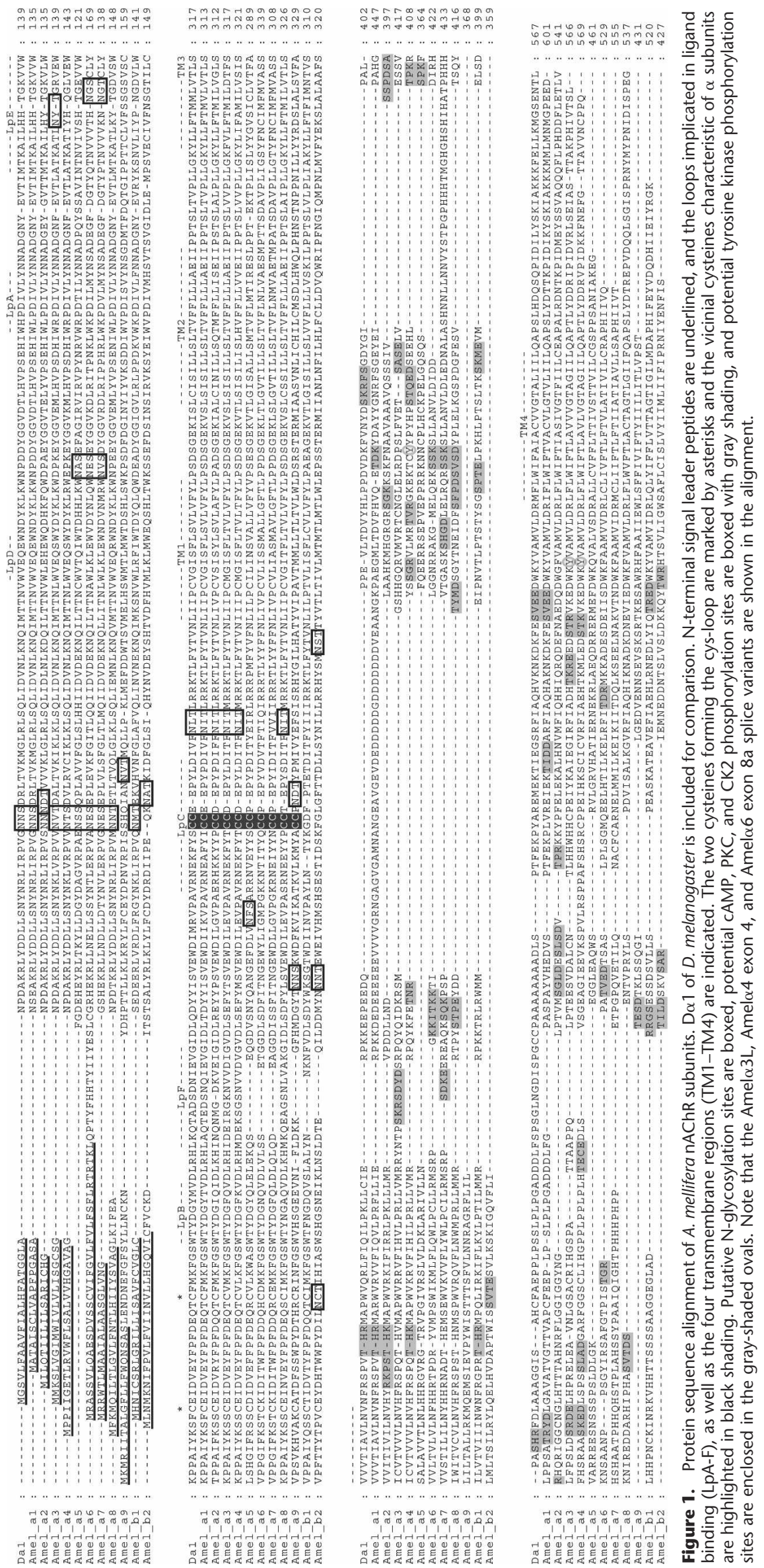

Genome Research 1423

www.genome.org 
but not ACh (Nauen et al. 2001). The involvement of nAChRs in honey bee behavior has also been investigated. Injection of the nAChR agonist, nicotine, showed that potentiation of the cholinergic system improves short term memory (Thany and Gauthier 2005) and injection of the nAChR antagonist, mecamylamine, inhibited olfactory learning or memory recall depending upon the site of injection (Lozano et al. 1996, 2001). Recently it has been demonstrated that one distinct nAChR subtype, which is $\alpha$-Btx sensitive, is involved in long-term memory, whereas a second subtype, which is $\alpha$-Btx insensitive, but is affected by mecamylamine, plays a role in retrieval processes (Dacher et al. 2005). Interestingly, this mirrors to a certain extent the mammalian central nervous system, where there are two predominant nAChR subtypes, the $\alpha 7$ and $\alpha 4 \beta 2$ receptors, that are $\alpha$-Btx sensitive and insensitive, respectively, and both receptor subtypes play a role in memory (for review, see Hogg et al. 2003). Since individual nAChR subunits can confer distinct pharmacological properties on a receptor (Romanelli and Gualtieri 2003), the multiple nAChR subtypes present in the honey bee nervous system are likely to be determined by their subunit composition. Identifying the full complement of honey bee nAChR subunits represents a critical step in understanding the variety of roles played by nAChRs in the honey bee nervous system and the exquisite repertoire of bee behavior, as well as in identifying particular targets of chemical compounds. Here we have used the $A$. mellifera genome to describe the complete honey bee nAChR gene family.

\section{Results}

Existence of 11 candidate $\mathrm{nAChR}$ subunit genes in the $A$. mellifera genome

Using TBLASTN, we identified 11 candidate nAChR subunits in the A. mellifera genome. The complete open-reading frames of each subunit were confirmed and completed by RT-PCR and
RACE-PCR. An alignment of their protein sequences shows that the honey bee nAChR candidate subunits possess features common to members of the cys-loop LGIC superfamily (Fig. 1). These include an $\mathrm{N}$-terminal signal peptide sequence, an extracellular $\mathrm{N}$-terminal region with conserved residues in loops A-F that are involved in ACh binding, the dicysteine loop (cys-loop) consisting of two disulphide-bond forming cysteines separated by 13 amino-acid residues, four transmembrane regions (TM1-TM4), and a highly variable intracellular loop between TM3 and TM4. As with other LGIC subunits, the Apis nAChR subunits also possess potential N-glycosylation sites within the extracellular Nterminal domain and phosphorylation sites within the TM3TM4 intracellular loop. In nine of the candidate subunits, two adjacent cysteine residues that are required for ACh binding (Kao and Karlin 1986) are present in loop C, defining them as $\alpha$ subunits. Due to the absence of the vicinial subunits, the remaining two candidates are designated $\beta$ subunits.

The honey bee nAChR subunits show substantial sequence similarity with known nAChR subunits, in particular, those of other insects. As shown in Table 1, Apis and Drosophila nAChR subunits can share up to $84 \%$ amino-acid identity. With regard to vertebrate nAChR subunits, they show $25 \%-38 \%$ identity. A phylogenetic tree demonstrating the relationship between Apis nAChR subunits and those of Drosophila and Anopheles indicates orthologous relationships between the honey bee and fruit fly/ mosquito subunits (Fig. 2). Previously characterized Apis nAChR subunits were named based on their closest human homolog (e.g., Apis $\alpha 3$ after the human $\alpha 3$ subunit [Thany et al. 2003]). However, several honey bee subunits do not have clear human homologs. Thus, to facilitate comparison of insect nAChR gene families and maintain consistency in insect subunit nomenclature, all honey bee nAChR subunits have been named after their Drosophila and Anopheles counterparts (any alternative nomenclature of Apis subunits is given in Table 1). As with Anopheles (Jones et al. 2005), the Apis counterpart of $\mathrm{D} \beta 2$ is of the $\alpha$ type (Amel $\alpha$ ). As is the case for Drosophila and Anopheles (Grauso et

Table 1. Percentage identity/similarity between $A$. mellifera and $D$. melanogaster nAChR subunit protein sequences

\begin{tabular}{|c|c|c|c|c|c|c|c|c|c|c|c|}
\hline Subunit & Amel $\alpha 1$ & Amel $\alpha 2$ & Amel $\alpha 3$ & Amel $\alpha 4$ & Amel $\alpha 5$ & Amel $\alpha 6$ & Amel $\alpha 7$ & Amel $\alpha 8$ & Amel $\beta 1$ & Amel $\beta 2$ & Amel $\alpha S$ \\
\hline & & (Apis $\alpha 2)$ & & & (Apis $\alpha 7-2)$ & & (Apis $\alpha 7-1)$ & (Apisa3) & & & \\
\hline & 9.7 & 9.7 & 5.24 & 7.22 & 15.8 & 2.27 & 14.14 & 5.9 & 14.14 & 9.3 & 9.3 \\
\hline Amel $\alpha 1$ & - & $47 / 62$ & $\frac{1.4}{51 / 63}$ & $49 / 61$ & $27 / 41$ & $30 / 44$ & $29 / 44$ & $49 / 62$ & $34 / 49$ & $10 / 27$ & $12 / 27$ \\
\hline $\mathrm{D} \alpha 1$ & $71 / 77$ & $51 / 66$ & $53 / 66$ & $50 / 63$ & $28 / 43$ & $31 / 46$ & $31 / 48$ & $52 / 65$ & $36 / 52$ & $10 / 27$ & $13 / 29$ \\
\hline Amel $\alpha 2$ & $47 / 62$ & - & $47 / 62$ & $45 / 61$ & $27 / 46$ & $31 / 47$ & $31 / 47$ & $48 / 63$ & $36 / 52$ & $11 / 30$ & $11 / 29$ \\
\hline $\mathrm{D} \alpha 2$ & $46 / 58$ & $74 / 82$ & $46 / 61$ & $43 / 59$ & $27 / 44$ & $30 / 48$ & $30 / 47$ & $47 / 62$ & $36 / 53$ & $11 / 29$ & $12 / 29$ \\
\hline Amel $\alpha 3$ & $51 / 63$ & $47 / 62$ & - & $64 / 74$ & $28 / 42$ & $31 / 46$ & $32 / 46$ & $54 / 65$ & $38 / 54$ & $11 / 27$ & $13 / 29$ \\
\hline $\mathrm{D} \alpha 3$ & $48 / 59$ & $44 / 60$ & $70 / 78$ & $58 / 68$ & $26 / 41$ & $30 / 45$ & $32 / 47$ & $50 / 63$ & $36 / 51$ & $10 / 26$ & $12 / 28$ \\
\hline Amel $\alpha 4$ & $49 / 61$ & $45 / 61$ & $64 / 74$ & - & $26 / 43$ & $31 / 46$ & $31 / 47$ & $50 / 64$ & $38 / 54$ & $11 / 28$ & $13 / 29$ \\
\hline $\mathrm{D} \alpha 4$ & $47 / 59$ & $43 / 60$ & $62 / 71$ & $78 / 84$ & $26 / 43$ & $30 / 46$ & $30 / 47$ & $51 / 63$ & $35 / 52$ & $11 / 29$ & $13 / 30$ \\
\hline Amel $\alpha 5$ & $27 / 41$ & $27 / 46$ & $28 / 42$ & $26 / 43$ & - & $33 / 52$ & $30 / 48$ & $27 / 44$ & $29 / 48$ & $15 / 32$ & $17 / 33$ \\
\hline $\mathrm{D} \alpha 5$ & $32 / 46$ & $32 / 48$ & $32 / 47$ & $31 / 48$ & $34 / 52$ & $58 / 69$ & $65 / 74$ & $32 / 47$ & $31 / 49$ & $13 / 29$ & $13 / 29$ \\
\hline Amel $\alpha 6$ & $30 / 44$ & $31 / 47$ & $31 / 46$ & $31 / 46$ & $33 / 52$ & - & $53 / 62$ & $33 / 48$ & $31 / 48$ & $14 / 32$ & $14 / 32$ \\
\hline $\mathrm{D} \alpha 6$ & $29 / 42$ & $30 / 47$ & $31 / 45$ & $31 / 46$ & $34 / 54$ & $73 / 82$ & $56 / 66$ & $34 / 48$ & $31 / 47$ & $14 / 32$ & $14 / 32$ \\
\hline Amel $\alpha 7$ & $29 / 44$ & $31 / 47$ & $32 / 46$ & $31 / 47$ & $30 / 48$ & $53 / 65$ & - & $30 / 46$ & $31 / 49$ & $13 / 30$ & $12 / 28$ \\
\hline $\mathrm{D} \alpha 7$ & $29 / 44$ & $31 / 46$ & $31 / 46$ & $31 / 47$ & $30 / 47$ & $56 / 69$ & $63 / 71$ & $31 / 47$ & $30 / 47$ & $13 / 29$ & $13 / 30$ \\
\hline Amel $\alpha 8$ & $49 / 62$ & $48 / 63$ & $54 / 65$ & $50 / 64$ & $27 / 44$ & $33 / 48$ & $30 / 46$ & - & $39 / 56$ & $12 / 31$ & $14 / 32$ \\
\hline$D \beta 2$ & $46 / 60$ & $47 / 64$ & $51 / 64$ & $49 / 63$ & $26 / 45$ & $30 / 47$ & $29 / 45$ & $70 / 82$ & $37 / 55$ & $13 / 31$ & $14 / 33$ \\
\hline Amel $\beta 1$ & $34 / 49$ & $36 / 52$ & $38 / 54$ & $38 / 54$ & $29 / 48$ & $31 / 48$ & $31 / 49$ & $39 / 56$ & - & $13 / 32$ & $13 / 30$ \\
\hline$D \beta 1$ & $35 / 51$ & $37 / 54$ & $38 / 54$ & $37 / 53$ & $29 / 48$ & $31 / 50$ & $30 / 49$ & $39 / 56$ & $84 / 88$ & $13 / 31$ & $13 / 30$ \\
\hline Amel $\beta 2$ & $10 / 27$ & $11 / 30$ & $11 / 27$ & $11 / 28$ & $15 / 32$ & $14 / 32$ & $13 / 30$ & $12 / 31$ & $13 / 32$ & - & $32 / 55$ \\
\hline$D \beta 3$ & $14 / 29$ & $16 / 32$ & $15 / 32$ & $16 / 33$ & $18 / 31$ & $17 / 36$ & $14 / 29$ & $16 / 34$ & $16 / 33$ & $17 / 34$ & $17 / 35$ \\
\hline Amel $\alpha 9$ & $12 / 27$ & $11 / 29$ & $13 / 29$ & $13 / 29$ & $17 / 33$ & $14 / 32$ & $12 / 28$ & $14 / 32$ & $13 / 30$ & $32 / 55$ & - \\
\hline
\end{tabular}

Alternative subunit nomenclature is given in parentheses and linkage groups are underlined. Proposed orthologs are shown in bold. 


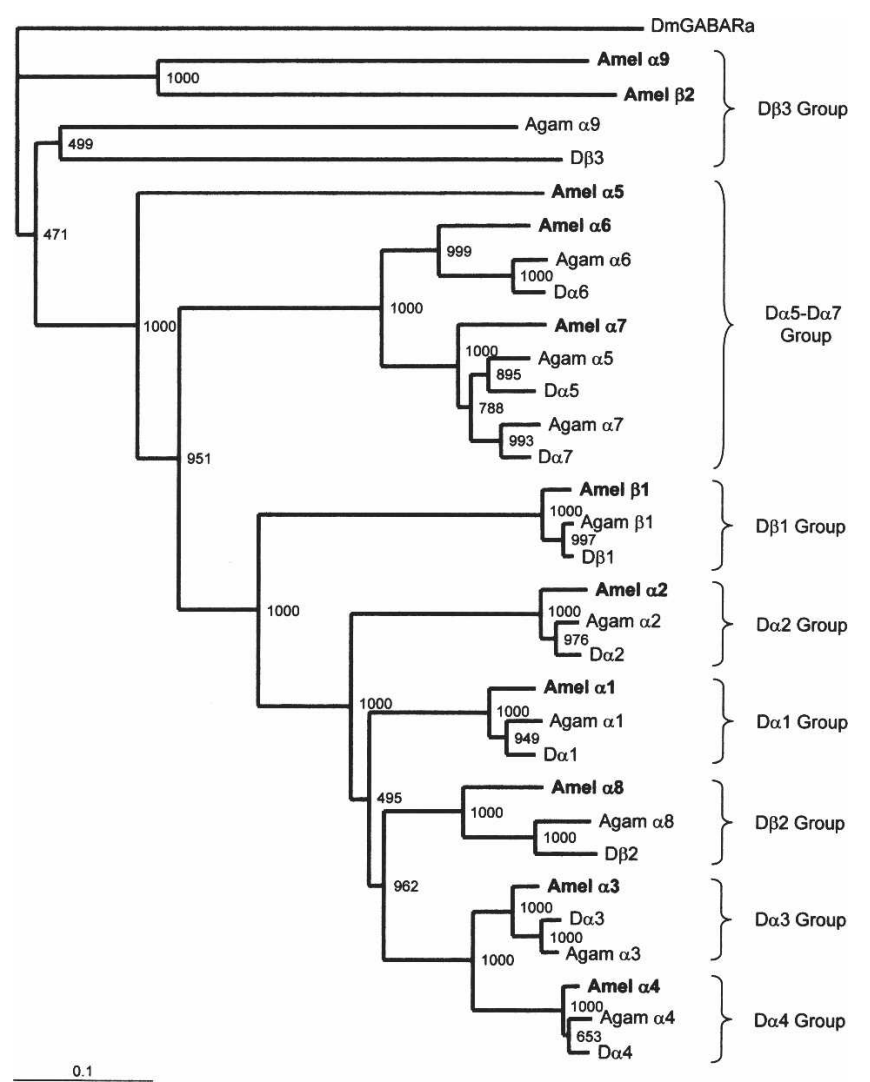

Figure 2. Tree showing relationships of $D$. melanogaster, A. gambiae, and $A$. mellifera nAChR subunit protein sequences. Numbers at each node signify bootstrap values with 1000 replicates and the scale bar represents substitutions per site. The $D$. melanogaster $\mathrm{GABA}_{\mathrm{A}}$ subunit (GenBank accession no. AAA28556) was used as an outgroup. The nAChR subunits shown in the tree (as well as GenBank accession nos.) are as follows: $D \alpha 1$ (CAA30172), D $\alpha 2$ (CAA36517), D $\alpha 3$ (CAA75688), D $\alpha 4$ (CAB77445), $\mathrm{D} \alpha 5$ (AAM13390), D $\alpha 6$ (AAM13392), D $\alpha 7$ (AAK67257), D 1 (CAA27641), D 22 (CAA39211), D 33 (CAC48166), Agam $\alpha 1$ (AY705394),

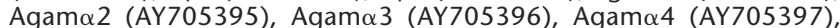
Agam $\alpha 5$ (AY705399), Agam $\alpha 6$ (AY705400), Agam $\alpha 7$ (AY705402), Agam $\alpha 8$ (AY705403), Agam $\alpha 9$ (AY705404), and Agam $\beta 1$ (AY705405). A. mellifera $\mathrm{nAChR}$ subunits are shown in boldface type.

al. 2002; Jones et al. 2005; Thany et al. 2005), three Apis subunits (Amel $\alpha$, Amel $\alpha 6$, and Amel $\alpha 7$ ) show close homology with the vertebrate $\alpha 7$ subunit, sharing 34\%, 44\%, and 40\% identity, respectively. Whereas Amel $\alpha 6$ is clearly orthologous to D $\alpha 6$ (Fig. 2), the Apis subunits analogous to $\mathrm{D} \alpha 5$ and $\mathrm{D} \alpha 7$ were not so easy to determine. We designated Amel $\alpha 7$ as the D $\alpha 7$ counterpart based on the fact that its N-terminal extracellular domain resembles that of $\mathrm{D} \alpha 7$ more closely than $\mathrm{D} \alpha 5$, showing $90 \%$ and $88 \%$ identity, respectively. The third $\alpha 7$-like subunit, Amel $\alpha 5$, is considerably distant from $\mathrm{D} \alpha 5$, as indicated by the long branch in the phylogenetic tree (Fig. 2).

Features particular to certain Drosophila and Anopheles nAChR subunits are also evident in their Apis counterparts (Fig. 1). For instance, as with $\mathrm{D} \alpha 1, \mathrm{D} \alpha 2, \mathrm{D} \alpha 3, \mathrm{D} \alpha 4$, and $\mathrm{D} \beta 2$, the corresponding Apis subunits (Amel $\alpha 1-$ Amel $\alpha 4$ and Amel $\alpha 8$ ) have an insertion in loop $\mathrm{F}$, which, interestingly, may contribute to imidacloprid interactions (Shimomura et al. 2004). The D $\alpha 1$, $\mathrm{D} \alpha 2$, and D $\beta 2$ genes, as well as the Anopheles orthologs, Agam $\alpha 1$, Agam $\alpha 2$, and Agam $\alpha 8$, are similarly arranged and tightly clus- tered within 200 and $220 \mathrm{~kb}$, respectively (Jones et al. 2005). In the Apis genome, only Amel $\alpha 1$ and Amel $\alpha 2$ are clustered, being situated within $120 \mathrm{~kb}$ of each other. Immunohistochemical and coimmunoprecipitation studies show that $\mathrm{D} \alpha 1, \mathrm{D} \alpha 2$, and $\mathrm{D} \beta 2$ are integral components of certain nAChR subtypes, leading to the suggestion that clustering may facilitate coordinate expression and coassembly of the nAChR subunits (Chamaon et al. 2002). The separation of the Apis $\mathrm{D} \beta 2$ ortholog Amel $\alpha 8$ from the cluster may thus result in diversification of receptor expression and coassembly. In line with this potential broadening of receptor complexity, studies indicate that $D \beta 2$ may also be part of a receptor subtype that includes $\mathrm{D} \beta 1$ but not $\mathrm{D} \alpha 1$ and $\mathrm{D} \alpha 2$ (Chamaon et al. 2002). Two other subunits, Amel $\alpha 7$ and Amel $\beta 1$, lie in close proximity to each other in the $A$. mellifera genome, both located in linkage group 14.14. This is also the case for the Anopheles orthologs Agam $\alpha 7$ and Agam $\beta 1$, which are both on chromosome $\mathrm{X}$ at map positions $5 \mathrm{D}$ and $5 \mathrm{C}$, respectively, whereas the Drosophila orthologs $\mathrm{D} \alpha 7$ and $\mathrm{D} \beta 1$ are located on different chromosomes, $\mathrm{X}$ and $3 \mathrm{~L}$, respectively (Jones et al. 2005).

Analysis of Drosophila and Anopheles nAChRs shows that each insect possesses a distantly related subunit sharing relatively low-sequence identity with other nAChR subunits. In the case of Drosophila, the subunit is of the non- $\alpha$ type (D $\beta 3$ ) (Lansdell and Millar 2002), whereas in Anopheles it is an $\alpha$ subunit (Agam $\alpha 9$ ) (Jones et al. 2005). Interestingly, the honey bee has two distantly related subunits, one $\alpha$ (Amel $\alpha 9)$ and the other non- $\alpha$ (Amel $\beta 2)$, which are designated members of the "D $\beta 3$ Group" (Fig. 2). It is interesting to speculate that duplication of a common ancestor gave rise to an $\alpha$ and a $\beta$ subunit with the $\alpha$ subunit being lost in the Drosophila lineage, the $\beta$ subunit disappearing in the Anopheles lineage, and both subunit types being retained in Apis. Indeed, the Amel $\alpha 9$ and Amel $\beta 2$ genes lie only within $10 \mathrm{~kb}$ of each other in the honey bee genome, suggesting that both subunits arose from an evolutionary recent duplication event from a common gene.

A comparison of Apis and Drosophila nAChR gene structures shows that only one ortholog pair (D $\alpha 6$ and Amel $\alpha 6)$ shares an identical set of exon-intron boundaries (Fig. 3). This conservation in gene structure is further highlighted by the Anopheles ortholog, Agam $\alpha 6$, also possessing the same exon composition (Jones et al. 2005). In other cases, Apis nAChR genes possess fewer introns than their Drosophila counterparts (e.g., Amel $\alpha 1$ and Amel $\beta 1$, which both possess two less than $\mathrm{D} \alpha 1$ and $\mathrm{D} \beta 1$, respectively), more introns (e.g., Amel $\alpha 3$, which has two more than $\mathrm{D} \alpha 3$ ), or the same number of introns (e.g., Amel $\alpha 4$ ). Both Amel $\alpha 5$ and Amel $\beta 2$ possess an uncommon exon-intron boundary within TM1. It is interesting to observe that in addition to having amino-acid sequences closely resembling the vertebrate $\alpha 7$ subunit, Amel $\alpha 5$, Amel $\alpha 6$, and Amel $\alpha 7$ possess exon-intron junctions found in mammalian, bird, and fish $\alpha 7$, as well as the closely related $\alpha 8$ subunits (Fig. 3) (Jones et al. 2003), indicating an ancient lineage for this receptor subtype.

\section{Splice variants increase Apis nicotinic receptor diversity}

Two Apis nAChR subunits, Amel $\alpha 4$ and Amel $\alpha 6$, have alternatively spliced exons most likely arising from tandem exon duplication (Kondrashov and Koonin 2001). As with D $\alpha 4$ and Agam $\alpha 4$ (Lansdell and Millar 2000; Jones et al. 2005), Amel $\alpha 4$ possesses two alternatives for exon 4 (denoted exon 4 and exon4') (Fig. 4A). However, whereas D $\alpha 6$ and Agam $\alpha 6$ have two alternatives for exon 3 (Grauso et al. 2002; Jones et al. 2005), Amel $\alpha 6$ has only a 


\section{Jones et al.}

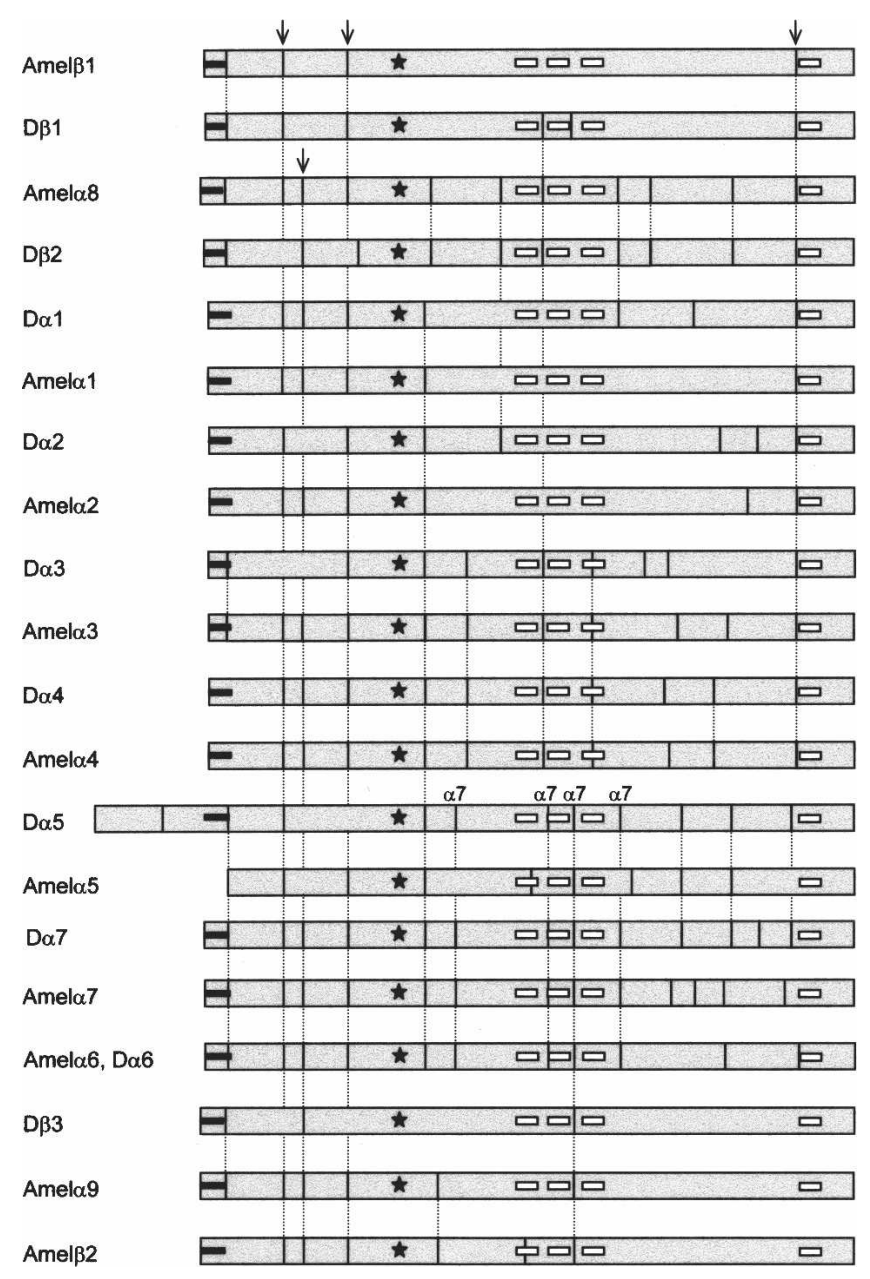

Figure 3. Exon composition of $D$. melanogaster and $A$. mellifera $\mathrm{nAChR}$ subunits. The $\mathrm{N}$-terminal signal peptide is shown as a bar, the cys-loop is denoted by a star, and the four transmembrane regions are marked as white boxes. Conserved exon-intron boundaries are indicated by broken lines. Boundaries highly conserved in nAChR genes of invertebrates and vertebrates are highlighted by arrows, while boundaries particular to the $\alpha 7$ subunit are also indicated.

single exon. For $\alpha 6$ exon 8, both Apis and Anopheles have two alternatives, while Drosophila has three, although the mosquito possesses exons analogous to D $\alpha 68 \mathrm{~b}$ and 8c (Jones et al. 2005), while the honey bee clearly possesses $8 \mathrm{a}$ and 8b-like exons (Fig. $4 \mathrm{~A})$.

As previously observed for Drosophila nAChRs, alternative splicing introduces amino-acid changes in functionally significant regions (Lansdell and Millar 2000; Grauso et al. 2002). For the two versions of Amel $\alpha 6$ exon 8, residues in the region linking TM2 with TM3 are altered (Fig. 4A). Since studies using chimeric vertebrate $\alpha 7 / \alpha 3$ receptors as well as site-directed mutagenesis in $\alpha 7$ have shown that this region is involved in coupling agonist binding to ion channel gating (Campos-Caro et al. 1996), alternative splicing of Amel $\alpha 6$ exon 8 may alter the response of ion channel function upon agonist binding.

Both D $\alpha 3$ and Agam $\alpha 3$ possess extraordinarily long intracellular domains between TM3 and TM4 (Schulz et al. 1998; Jones et al. 2005). However, the Apis ortholog, Amel $\alpha 3$, does not have such an extended region (Fig. 1), although use of different splice sites gives rise to two variants, Amel $\alpha 3 \mathrm{~L}$ (long variant) and Amel 3 S (short variant), which have intracellular domains differing in size by 13 amino-acid residues (Fig. 4C). It is worth noting that Amel $\alpha 3 \mathrm{~L}$ has two extra phosphorylation sites. Since phosphorylation of the intracellular loop is involved in regulating several aspects of receptor function such as desensitization and aggregation (Hopfield et al. 1988; Borges and Ferns 2001), the two splice variants have the potential to alter several receptor properties (Schulz et al. 1998; Jones et al. 2005).

Truncated transcripts for several Drosophila nAChR subunits have also been described. For instance, D $\alpha 4$ cDNAs lacking exon $2\left(\mathrm{D} \alpha 4^{\Delta \text { exon2}}\right.$ ) have been identified (Lansdell and Millar 2000), while in other cases, omission of exon 4 from $\mathrm{D} \alpha 4\left(\mathrm{D} \alpha 4^{\Delta \text { exon } 4}\right)$ and exon 5 from $\mathrm{D} \alpha 5\left(\mathrm{D} \alpha 5^{\Delta \text { exon5}}\right)$ result in frameshifts and the introduction of premature stop codons (Lansdell and Millar 2000; Grauso et al. 2002). For D $\alpha 7$, a premature stop codon is introduced by lack of splicing intron 5 (Grauso et al. 2002). RTPCR was performed to determine whether similar truncated transcripts could be detected for the corresponding Apis nAChR subunits. As with Anopheles (Jones et al. 2005), truncated honey bee cDNAs analogous to $\mathrm{D} \alpha 4^{\Delta \text { exon2 }}$ and $\mathrm{D} \alpha 5^{\Delta \text { exon5 }}$ were not detected, whereas Amel4 $4^{\Delta \text { exon4}}$ and truncated Amel $\alpha 7$ transcripts were identified, both having premature stop codons (Fig. 4B). In addition, RT-PCR analysis revealed a novel truncated variant, where lack of splicing intron 9 in Amel $\alpha 3$ results in the introduction of a premature stop codon (Fig. 4C). It remains to be determined whether these truncated transcripts are removed by a process such as nonsense-mediated decay, which rapidly degrades mRNAs with premature stop codons (Hillman et al. 2004). Otherwise, if the truncated transcripts are translated, it would be of interest to determine the functional role of the resulting proteins. Perhaps they regulate receptor expression in a similar manner to a truncated variant of the mouse $\alpha 7$ subunit, which acts as a dominant negative when cotransfected with full-length $\alpha 7$ in HEK 293 cells (Saragoza et al. 2003). Alternatively, the truncated receptors may be modulating cholinergic synaptic transmission by acting as an ACh "sponge" in a manner similar to that of the molluscan ACh-binding protein (Smit et al. 2003). However, the truncated receptors lack some of the loops important for ligand binding, most notably loop C, which is crucial for ACh interaction; thus, their ability to bind $\mathrm{ACh}$ is questionable and remains to be determined. The novel truncated Amel 33 transcript (Fig. $4 \mathrm{C}$ ), however, is the first abbreviated insect variant reported to possess all ligand-binding loops as well as the first three transmembrane domains. With the complete N-terminal extracellular domain as well as TM2, which lines the ion channel, the truncated transcript may well assemble with other subunits to form a functional receptor. Since analysis of subunit mutants suggests a role for TM4 in channel gating (Mitra et al. 2004), it is likely that the Amel $\alpha 3$ variant would have a profound effect on ion channel properties. The Amel $\alpha 3$ truncation also possesses four putative phosphorylation sites (Fig. 4C); thus, it may serve to diversify several characteristics of receptor function.

\section{The two Amel $\alpha 4$ splice variants are differentially expressed}

RT-PCR was performed to determine which of the 11 Apis nAChR subunits as well as all splice variants are transcribed at different stages of honey bee development, including four larval stages $\left(\mathrm{L}_{0}-\mathrm{L}_{3}\right)$, three pupal stages $\left(\mathrm{P}_{1}, \mathrm{P}_{3}\right.$, and $\left.\mathrm{P}_{4}\right)$, and the following tissues from adults: mushroom bodies, optic lobes, brains, head,

\section{Genome Research}

www.genome.org 
A

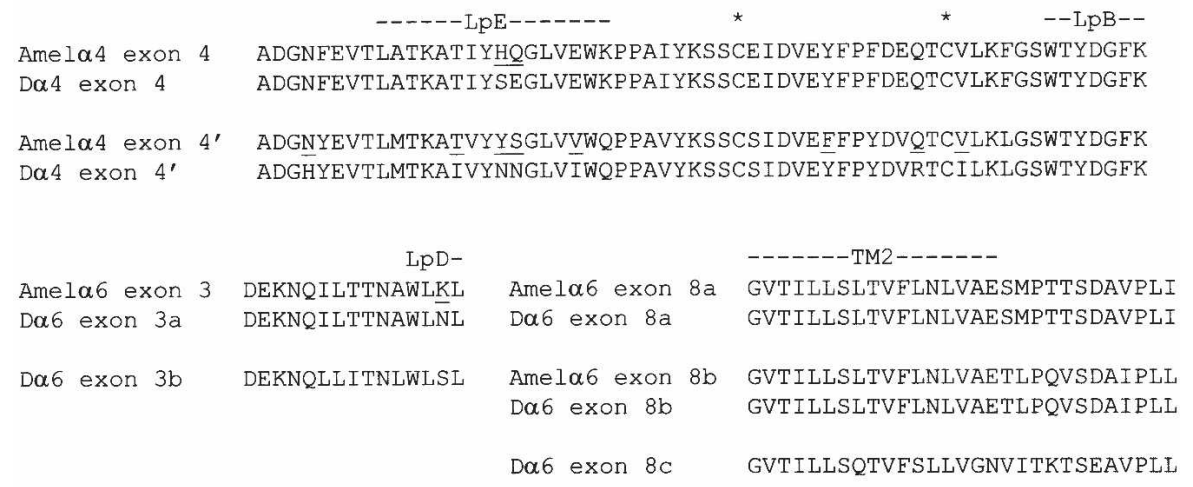

B

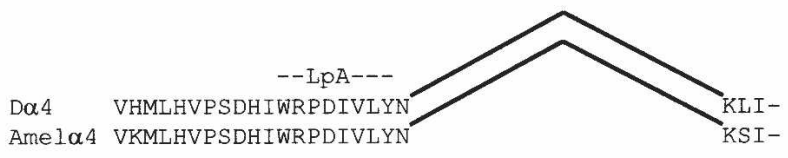

Da7 * CKIDITWFPEDDQRCEMKFGSWTYDGFOUTTQLLS-

Amel $\alpha 7$ CKIDITWFPFDDQRCEMKFGSWTYDGF

\section{C}

Ame $1 \alpha 3 \mathrm{~L}$

and

Ame $1 \alpha 3 S$

TM3

HFRS PQTHVMAPWVRRVF I HVLPRLLVMRRYNTPSKRSDYDSRPQYQID

HERS PQTHVMAPWVRRVFIHVLPRLLVMRR . . . . . . PQYQID

TM4
Truncated Amel $\alpha 3$

HFRSPQTHVMAPWVRRVFIHVLPRLLVMRRYNT

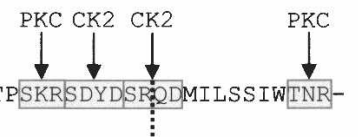

Figure 4. Splice variants of $A$. mellifera nAChR subunits. $(A)$ Comparison of alternative exons of $D$. melanogaster and A. mellifera. Apis residues that differ from those of the orthologous Drosophila exon are underlined. $(B)$ Conservation of truncated $\mathrm{nAChR}$ transcripts between $D$. melanogaster and A. mellifera. Omission of exon 4 of $\mathrm{D} \alpha 4$ and Amel $\alpha 4$ results in a frameshift and premature termination of translation, while nonsplicing of intron 5 of $\mathrm{D} \alpha 7$ and the equivalent intron of Amel $\alpha 7$ introduces a loss of the reading frame and a premature stop codon. (C) Novel splice variants in Apis nAChRs. The TM3 and TM4 domains are represented schematically, while the sequence of a portion of the intervening intracellular loop is shown highlighting the three splice variants, and the remainder of the loop is represented by a black bar. Loops involved in ligand binding and transmembrane regions are indicated, while the cys-loop is marked by asterisks. Potential phosphorylation sites are highlighted by gray shading and broken lines mark the start of altered reading frames resulting from unspliced introns.

and whole bodies. All 11 subunits, as well as all splice variants, are transcribed in each developmental stage and tissue tested (see Supplemental material) with one exception. Amel $\alpha 4$ exon 4 transcripts were detected in all stages and tissues, whereas transcripts of Amel $\alpha 4$ exon4' splice variants were not observed in larvae and were particularly more abundant in the mushroom bodies, optic lobes, and brain (see Supplemental material). Since alternative splicing of Amel $\alpha 4$ exon4 substitute residues in the vicinity of the cys-loop, which has been shown to be important for complete receptor assembly (Green and Wanamaker 1997) and radioligand-binding assays, indicate that $\mathrm{D} \alpha 4$ with exon $4^{\prime}$ assembles less efficiently than with exon4 (Lansdell and Millar 2000), Amel $\alpha 4$ exon $4^{\prime}$ subunits may serve to modulate receptor assembly during the later stages of honey bee development and in tissues rich in neural activity such as the mushroom bodies and optic lobes.

\section{Amel $\alpha 6$ undergoes A-to-I pre-mRNA editing}

Pre-mRNA A-to-I editing modifies select adenosine (A) residues to inosine (I) in transcripts, which is interpreted as guanosine $(G)$, thereby generating mRNA with a nucleotide composition that differs from the corresponding genomic DNA (Seeburg 2002). RNA editing has been observed in several Drosophila nAChR subunits, including two sites in loop D of $\mathrm{D} \beta 1$, one site in TM2 of $\mathrm{D} \beta 2$, one site in TM3, three sites in TM4 of $\mathrm{D} \alpha 5$, and seven sites in loops $\mathrm{E}$ to $\mathrm{F}$ in D $\alpha 6$ (Grauso et al. 2002; Hoopengardner et al. 2003; Sattelle et al. 2005). To determine whether orthologous Apis nAChR subunits are also RNA edited, the equivalent regions of Amel $\beta 1$, Amel $\alpha 8$, Amel $\alpha 5$, and Amel $\alpha 6$ were amplified with high-fidelity proofreading DNA polymerase. For Amel $\beta 1$, Amel $\alpha 8$, and Amel $\alpha 5$, the sequences of the resulting amplification products were identical to those of genomic DNA with no indication of A-to-G changes (data not shown), showing that these regions of the three subunits are not RNA edited.

For Amel $\alpha 6$, however, six RNAediting sites were observed, two of which are conserved in the Drosophila and Heliothis virescens orthologs, D $\alpha 6$ and $\mathrm{Hv} \alpha 7-2$, respectively (Grauso et al. 2002) (Fig. 5). The genomic DNA and adult cDNA sequence traces shown in Figure 5 were taken from the same individual bee, indicating that sequence variation likely arose at the RNA level, thereby eliminating the possibility that they are polymorphisms. Editing at five of the six sites alters amino acid residues, all of which are situated in functionally significant regions. For instance, an N-glycosylation site in loop $\mathrm{E}$ is eliminated by one case of editing. Since loop E contributes to ligand binding and N-glycosylation has also been linked to ligand binding as well as channel desensitization and conductance (Corringer et al. 2000; Nishizaki 2003), editing at this site has considerable potential to alter receptor function. In the remaining cases, editing alters residues near or within the cys-loop, which, like alternative splicing of Amel $\alpha 4$ exon 4, may affect receptor assembly. Analysis of Amel $\alpha 6$ editing at different stages of honey bee development shows that in larvae, five of the six sites undergo editing, the extent of which increases throughout development so that in adults, four sites are predominantly edited. In pupae, from $\mathrm{P}_{3}$ onward, editing was observed at the sixth site, which increases considerably the potential diversity of subunit isoforms, as a lysine residue can be converted to either arginine, glutamic acid, or glycine. Interest- 


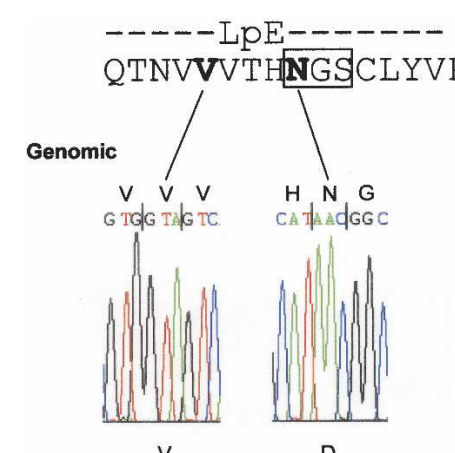

Lo
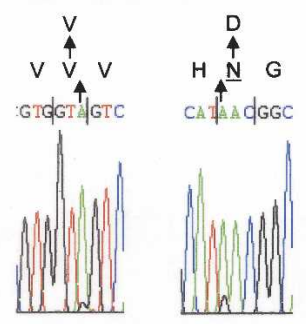

P1
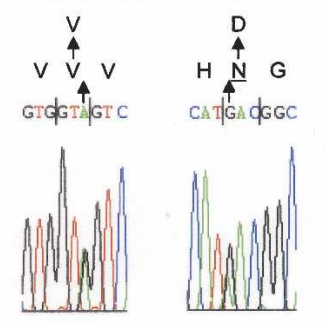

Adult
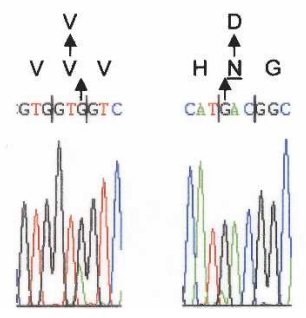

Figure 5. RNA editing of Amel $\alpha 6$. Sequencing traces of RT-PCR products from larval $\left(\mathrm{L}_{0}\right)$, pupal $\left(\mathrm{P}_{1}\right)$, and adult stages are compared with amplified genomic DNA. Editing is shown by mixed A and $G$ signals. Amino acids also affected by editing in $D$. melanogaster and $H$. virescens are underlined. The edited region of Amel $\alpha 6$ is included with loop E indicated, N-glycosylation sites boxed and a cysteine, which is part of the cys-loop, marked by an asterisk. Amino acids targeted by editing are highlighted in bold.

ingly, the elevated editing in the later stages of development is consistent with findings that RNA editing is particularly important in the nervous system function of Drosophila adults (Palladino et al. 2000) and that the highest levels of RNA editing are seen in adult flies (Keegan et al. 2005).

\section{Discussion}

We have used the available $A$. mellifera genome information to complete the characterization of the honey bee nAChR gene family, thus describing the first complete set of Hymenoptera nAChR subunits and the third insect nAChR gene family following those of the two Diptera, A. gambiae (Jones et al. 2005) and D. melanogaster (Sattelle et al. 2005). The three insect species represent $\sim 280$ million years of evolution (Carpenter and Burnham 1985; De Gregorio and Lemaitre 2002) where the nAChR gene family has remained compact with $A$. mellifera having 11 genes encoding nAChR subunits, whereas both $D$. melanogaster and A. gambiae possess 10 genes (Jones et al. 2005; Sattelle et al. 2005). The nAChR subunit composition of Apis most closely resembles that of Anopheles in that both possess nine $\alpha$ and one $\beta$ subunit, while Drosophila has seven $\alpha$ and three $\beta$. The extra honey bee subunit is a $\beta$ subunit (Amel $\beta 2$ ) making A. mellifera only the second insect known to possess more than one non- $\alpha$ type subunit.

The characterization of the full complement of honey bee nAChR subunits presents an important basis for associating particular nAChR subtypes with key aspects of behavior, identifying receptor subtypes targeted by neonicotinoids as well as developing insecticides with improved selectivity. Indeed, comparison of complete insect nAChR gene families has identified a highly divergent subunit group (the D 33 group) as well as species-specific proteome diversification arising from alternative splicing and RNA editing, all of which represent promising subunit differences to target for future rational insecticide design. While studies using heterologous expression systems such as Xenopus laevis oocytes have proven instructive in characterizing vertebrate nAChRs (Corringer et al. 2000) and low levels of functional expression of an insect $\alpha$ subunit, $\alpha \mathrm{L} 1$, have been observed in Xenopus oocytes (Marshall et al. 1990), expression of functional insect nAChRs has so far proven elusive (Sattelle et al. 2005). Nevertheless, Drosophila nAChR $\alpha$ subunits can form robust functional channels when coexpressed with a vertebrate $\beta 2$ subunit (Bertrand et al. 1994) and studies on such hybrid receptors have provided insights into the selectivity of neonicotinoids for insect nAChRs over those of vertebrates (Matsuda et al. 1998; Ihara et al. 2003), regions of subunit proteins involved in neonicotinoid interactions (Shimomura et al. 2002, 2003, 2004), and the actions of different neonicotinoids (Ihara et al. 2004). Also, computer models of insect nAChRs have been recently generated, which permit docking experiments to assess interactions with compounds of interest (Sattelle et al. 2005). Similar studies combining functional expression with molecular modeling of Apis nAChRs are likely to prove useful in screening for novel compounds that show low selectivity for honey bee receptors and in dissecting the mechanisms of insecticide actions and selectivity on nAChRs.

\section{Methods}

\section{Identification of $\mathrm{nAChR}$ subunits in the $A$. mellifera genome}

To identify putative nAChR subunits, we screened the $A$. mellifera genome (database version $34.2 \mathrm{~b}$ available at http://www. ensembl.org/Apis_mellifera/index.html and assembly version 3.0 available at http://www.ensembl.org/Apis_mellifera/) with each of the $10 \mathrm{D}$. melanogaster $\mathrm{nAChR}$ subunit cDNA sequences using the TBLASTN algorithm (Altschul et al. 1990). Candidate honey bee $\mathrm{nAChR}$ subunits were identified based on their considerable sequence homology with previously characterized nAChR subunits (sequences with lowest similarity had E-value 1e-21), particularly at the N-terminal ligand-binding domain and the four transmembrane regions. RT-PCRs were performed to verify the open-reading frame sequences of each subunit. Since BLAST was unable to identify the highly variable N-terminal signal peptides, 5'-RACE, using the Roche 5'/3' RACE kit, was performed to complete the nAChR subunit sequences.

\section{Genome Research}

www.genome.org 
The multiple protein-sequence alignment was constructed with CLUSTALX (Thompson et al. 1997) using the slow-accurate mode with a gap-opening penalty of 10 and a gap-extension penalty of 0.1 as well as applying the Gonnet 250 protein weight matrix (Benner et al. 1994). The protein alignment was viewed using GeneDoc (http://www.psc.edu/biomed/genedoc). The neighbor-joining method (Saitou and Nei 1987) and bootstrap resampling (Felsenstein 1985), available with the CLUSTALX program, were used to construct a phylogenetic tree, which was then displayed using the TreeView application (Page 1996). Signal peptide cleavage sites were predicted using the SignalP 3.0 server (Dyrlov Bendtsen et al. 2004) and membrane-spanning regions were predicted using the TMpred program (available at http:// www.ch.embnet.org/software/TMPRED_form.html). The PROSITE database (Falquet et al. 2002) was used to identify potential cyclic AMP (cAMP), protein kinase C (PKC), CK2, and potential kinase phosphorylation sites.

\section{Dissection of $A$. mellifera tissues}

Honey bee pupae and larvae were taken from the hive. Their developmental stage was determined using pigmentations of eyes, joints, and legs as described by Winston (1987). Adult honey bees were collected at the entrance of the hive. Bees were anaesthetized on ice and dissection of $A$. mellifera tissues were performed under a stereomicroscope in sterile $1 \mathrm{X}$ PBS. The brain was removed from the capsule head free of cuticle and trachea. When necessary, brain parts were separated manually. The tissues were then frozen in liquid nitrogen before RNA and genomic DNA extraction.

\section{Reverse transcription and polymerase chain reaction}

Genomic DNA was extracted from adult bees using the DNeasy Tissue Kit (Qiagen) and total RNA was extracted from various developmental stages and tissues using the RNeasy Mini Kit (Qiagen). First-strand cDNA was synthesized from $1 \mu \mathrm{g}$ of total RNA using Superscript III First-Strand Synthesis Super Mix (Invitrogen). Nested RT-PCR reactions were performed to detect transcript of all honey bee nAChR subunits and variants. Primer pairs that recognize different exons were used to allow identification of cDNA-specific products (see Supplemental material for PCR primer sequences). The PCR reactions were performed in a total volume of $50 \mu \mathrm{L}$ composed of Taq polymerase and 1X PCR buffer (Sigma), $0.2 \mathrm{mM}$ dNTP mix (Roche), $0.4 \mu \mathrm{M}$ each primer, and 2 $\mu \mathrm{L}$ first-strand cDNA template. The nested PCR approach involved two reactions each with 30 cycles of $95^{\circ} \mathrm{C}$ for $30 \mathrm{sec}, 55^{\circ} \mathrm{C}$ for $30 \mathrm{sec}$, and $72^{\circ} \mathrm{C}$ for $30 \mathrm{sec} / 500 \mathrm{bp}$ amplified. The first PCR was used at a final dilution of one in 5000 as template for the second nested PCR reaction. For RNA-editing analysis, nested PCR using the proofreading Pfu Turbo DNA polymerase (Stratagene) in $2 \times 30$-cycle reactions was performed on at least two independently made first-strand cDNAs. PCR products were analyzed by electrophoresis in a TAE gel and then purified using the QIAquick Gel Extraction Kit (Qiagen) before being sequenced by the dye termination method at the Biochemistry Sequencing Facility, University of Oxford.

\section{Acknowledgments}

We are indebted to the A. mellifera Genome Project (Human Genome Sequencing Center), which provided the starting point for this study. We thank Sandrine Paute for technical support. We also thank Ryszard Maleszka and Chris Ponting for encouragement, support, and helpful comments on the manuscript.

\section{References}

Altschul, S.F., Gish, W., Miller, W., Myers, E.W., and Lipman, D.J. 1990. Basic local alignment search tool. J. Mol. Biol. 215: 403-410.

Benner, S.A., Cohen, M.A., and Gonnet, G.H. 1994. Amino acid substitution during functionally constrained divergent evolution of protein sequences. Protein Eng. 7: 1323-1332.

Bertrand, D., Ballivet, M., Gomez, M., Bertrand, S., Phannavong, B., and Gundelfinger, E.D. 1994. Physiological properties of neuronal nicotinic receptors reconstituted from the vertebrate $\beta 2$ subunit and Drosophila a subunits. Eur. J. Neurosci. 6: 869-875.

Borges, L.S. and Ferns, M. 2001. Agrin-induced phosphorylation of the acetylcholine receptor regulates cytoskeletal anchoring and clustering. J. Cell Biol. 153: 1-12.

Breer, H. and Sattelle, D.B. 1987. Molecular properties and functions of insect acetylcholine receptors. J. Insect Physiol. 33: 771-790.

Campos-Caro, A., Sala, S., Ballesta, J.J., Vicente-Agullo, F., Criado, M., and Sala, F. 1996. A single residue in the M2-M3 loop is a major determinant of coupling between binding and gating in neuronal nicotinic receptors. Proc. Natl. Acad. Sci. 93: 6118-6123.

Carpenter, F. and Burnham, L. 1985. The geological record of insects. Annu. Rev. Earth Planet. Sci. 13: 297-314.

Chamaon, K., Smalla, K.H., Thomas, U., and Gundelfinger, E.D. 2002. Nicotinic acetylcholine receptors of Drosophila: Three subunits encoded by genomically linked genes can co-assemble into the same receptor complex. J. Neurochem. 80: 149-157.

Corringer, P.J., Le Novere, N., and Changeux, J.P. 2000. Nicotinic receptors at the amino acid level. Annu. Rev. Pharmacol. Toxicol. 40: 431-458.

Dacher, M., Lagarrigue, A., and Gauthier, M. 2005. Antennal tactile learning in the honeybee: Effect of nicotinic antagonists on memory dynamics. Neuroscience 130: 37-50.

Decourtye, A., Devillers, J., Cluzeau, S., Charreton, M., and Pham-Delegue, M.H. 2004. Effects of imidacloprid and deltamethrin on associative learning in honeybees under semi-field and laboratory conditions. Ecotoxicol. Environ. Saf. 57: 410-419.

Déglise, P., Grunewald, B., and Gauthier, M. 2002. The insecticide imidacloprid is a partial agonist of the nicotinic receptor of honeybee Kenyon cells. Neurosci. Lett. 321: 13-16.

De Gregorio, E. and Lemaitre, B. 2002. The mosquito genome: The post-genomic era opens. Nature 419: 496-497.

Dyrlov Bendtsen, J., Nielsen, H., Von Heijne, G., and Brunak, S. 2004. Improved prediction of signal peptides: SignalP 3.0. J. Mol. Biol. 340: 783-795.

Falquet, L., Pagni, M., Bucher, P., Hulo, N., Sigrist, C.J., Hofmann, K., and Bairoch, A. 2002. The PROSITE database, its status in 2002. Nucleic Acids Res. 30: 235-238.

Felsenstein, J. 1985. Confidence limits on phylogenies: An approach using the bootstrap. Evolution Int. J. Org. Evolution 39: 783-791.

Goldberg, F., Grunewald, B., Rosenboom, H., and Menzel, R. 1999. Nicotinic acetylcholine currents of cultured Kkenyon cells from the mushroom bodies of the honey bee Apis mellifera. J. Physiol. 514: $759-768$.

Grauso, M., Reenan, R.A., Culetto, E., and Sattelle, D.B. 2002. Novel putative nicotinic acetylcholine receptor subunit genes, $\mathrm{D} \alpha 5, \mathrm{D} \alpha 6$ and $\mathrm{D} \alpha 7$, in Drosophila melanogaster identify a new and highly conserved target of adenosine deaminase acting on RNA-mediated A-to-I pre-mRNA editing. Genetics 160: 1519-1533.

Green, W.N. and Wanamaker, C.P. 1997. The role of the cystine loop in acetylcholine receptor assembly. J. Biol. Chem. 272: 20945-20953.

Guez, D., Suchail, S., Gauthier, M., Maleszka, R., and Belzunces, L.P. 2001. Contrasting effects of imidacloprid on habituation in 7- and 8-day-old honeybees (Apis mellifera). Neurobiol. Learn. Mem. 76: $183-191$.

Hillman, R.T., Green, R.E., and Brenner, S.E. 2004. An unappreciated role for RNA surveillance. Genome Biol. 5: R8.

Hogg, R.C., Raggenbass, M., and Bertrand, D. 2003. Nicotinic acetylcholine receptors: From structure to brain function. Rev. Physiol. Biochem. Pharmacol. 147: 1-46.

Hoopengardner, B., Bhalla, T., Staber, C., and Reenan, R. 2003. Nervous system targets of RNA editing identified by comparative genomics. Science 301: 832-836.

Hopfield, J.F., Tank, D.W., Greengard, P., and Huganir, R.L. 1988. Functional modulation of the nicotinic acetylcholine receptor by tyrosine phosphorylation. Nature 336: 677-680.

Ihara, M., Matsuda, K., Otake, M., Kuwamura, M., Shimomura, M., Komai, K., Akamatsu, M., Raymond, V., and Sattelle, D.B. 2003. Diverse actions of neonicotinoids on chicken $\alpha 7, \alpha 4 \beta 2$ and Drosophila-chicken SAD $\beta 2$ and ALS $\beta 2$ hybrid nicotinic acetylcholine receptors expressed in Xenopus laevis oocytes. Neuropharmacology 45: $133-144$. 
Ihara, M., Matsuda, K., Shimomura, M., Sattelle, D.B., and Komai, K. 2004. Super agonist actions of clothianidin and related compounds on the SAD $\beta 2$ nicotinic acetylcholine receptor expressed in Xenopus laevis oocytes. Biosci. Biotechnol. Biochem. 68: 761-763.

Jones, A.K. and Sattelle, D.B. 2004. Functional genomics of the nicotinic acetylcholine receptor gene family of the nematode, Caenorhabditis elegans. Bioessays 26: 39-49.

Jones, A.K., Elgar, G., and Sattelle, D.B. 2003. The nicotinic acetylcholine receptor gene family of the pufferfish, Fugu rubripes. Genomics 82: 441-451.

Jones, A.K., Grauso, M., and Sattelle, D.B. 2005. The nicotinic acetylcholine receptor gene family of the malaria mosquito, Anopheles gambiae. Genomics 85: 176-187.

Kao, P.N. and Karlin, A. 1986. Acetylcholine receptor binding site contains a disulfide cross-link between adjacent half-cystinyl residues. J. Biol. Chem. 261: 8085-8088.

Karlin, A. 2002. Emerging structure of the nicotinic acetylcholine receptors. Nat. Rev. Neurosci. 3: 102-114.

Keegan, L.P., Brindle, J., Gallo, A., Leroy, A., Reenan, R.A., and O'Connell, M.A. 2005. Tuning of RNA editing by ADAR is required in Drosophila. EMBO J. 24: 2183-2193.

Kondrashov, F.A. and Koonin, E.V. 2001. Origin of alternative splicing by tandem exon duplication. Hum. Mol. Genet. 10: 2661-2669.

Lambin, M., Armengaud, C., Raymond, S., and Gauthier, M. 2001. Imidacloprid-induced facilitation of the proboscis extension reflex habituation in the honeybee. Arch. Insect Biochem. Physiol. 48: $129-134$.

Lansdell, S.J. and Millar, N.S. 2000. Cloning and heterologous expression of $\mathrm{D} \alpha 4$, a Drosophila neuronal nicotinic acetylcholine receptor subunit: Identification of an alternative exon influencing the efficiency of subunit assembly. Neuropharmacology 39: 2604-2614.

Lansdell, S.J. and Millar, N.S. 2002. Dß3, an atypical nicotinic acetylcholine receptor subunit from Drosophila: Molecular cloning, heterologous expression and coassembly. J. Neurochem. 80: $1009-1018$.

Lee, D. and O'Dowd, D.K. 1999. Fast excitatory synaptic transmission mediated by nicotinic acetylcholine receptors in Drosophila neurons. J. Neurosci. 19: 5311-5321.

Lozano, V.C., Bonnard, E., Gauthier, M., and Richard, D. 1996. Mecamylamine-induced impairment of acquisition and retrieval of olfactory conditioning in the honeybee. Behav. Brain Res. 81: $215-222$.

Lozano, V.C., Armengaud, C., and Gauthier, M. 2001. Memory impairment induced by cholinergic antagonists injected into the mushroom bodies of the honeybee. J. Comp. Physiol. [A] 187: 249-254.

Marshall, J., Buckingham, S.D., Shingai, R., Lunt, G.G., Goosey, M.W., Darlison, M.G., Sattelle, D.B., and Barnard, E.A. 1990. Sequence and functional expression of a single $\alpha$ subunit of an insect nicotinic acetylcholine receptor. EMBO J. 9: 4391-4398.

Matsuda, K., Buckingham, S.D., Freeman, J.C., Squire, M.D., Baylis, H.A., and Sattelle, D.B. 1998. Effects of the $\alpha$ subunit on imidacloprid sensitivity of recombinant nicotinic acetylcholine receptors. $\mathrm{Br}$. J. Pharmacol. 123: 518-524.

Matsuda, K., Buckingham, S.D., Kleier, D., Rauh, J.J., Grauso, M., and Sattelle, D.B. 2001. Neonicotinoids: Insecticides acting on insect nicotinic acetylcholine receptors. Trends Pharmacol. Sci. 22: 573-580.

Millar, N.S. 2003. Assembly and subunit diversity of nicotinic acetylcholine receptors. Biochem. Soc. Trans. 31: 869-874.

Mitra, A., Bailey, T.D., and Auerbach, A.L. 2004. Structural dynamics of the M4 transmembrane segment during acetylcholine receptor gating. Structure 12: 1909-1918.

Nauen, R., Ebbinghaus-Kintscher, U., and Schmuck, R. 2001. Toxicity and nicotinic acetylcholine receptor interaction of imidacloprid and its metabolites in Apis mellifera (Hymenoptera: Apidae). Pest Manag. Sci. 57: $577-586$.

Nishizaki, T. 2003. N-glycosylation sites on the nicotinic ACh receptor subunits regulate receptor channel desensitization and conductance. Brain Res. Mol. Brain Res. 114: 172-176.

Page, R.D. 1996. TreeView: An application to display phylogenetic trees on personal computers. Comput. Appl. Biosci. 12: 357-358.

Palladino, M.J., Keegan, L.P., O'Connell, M.A., and Reenan, R.A. 2000.
A-to-I pre-mRNA editing in Drosophila is primarily involved in adult nervous system function and integrity. Cell 102: 437-449.

Robinson, G.E., Fahrbach, S.E., and Winston, M.L. 1997. Insect societies and the molecular biology of social behavior. Bioessays 19: 1099-1108.

Romanelli, M.N. and Gualtieri, F. 2003. Cholinergic nicotinic receptors: Competitive ligands, allosteric modulators, and their potential applications. Med. Res. Rev. 23: 393-426.

Saitou, N. and Nei, M. 1987. The neighbor-joining method: A new method for reconstructing phylogenetic trees. Mol. Biol. Evol. 4: 406-425.

Saragoza, P.A., Modir, J.G., Goel, N., French, K.L., Li, L., Nowak, M.W., and Stitzel, J.A. 2003. Identification of an alternatively processed nicotinic receptor $\alpha 7$ subunit RNA in mouse brain. Brain Res. Mol. Brain Res. 117: 15-26.

Sattelle, D.B., Jones, A.K., Sattelle, B.M., Matsuda, K., Reenan, R., and Biggin, P.C. 2005. Edit, cut and paste in the nicotinic acetylcholine receptor gene family of Drosophila melanogaster. Bioessays 27: 366-376.

Schulz, R., Sawruk, E., Mulhardt, C., Bertrand, S., Baumann, A., Phannavong, B., Betz, H., Bertrand, D., Gundelfinger, E.D., and Schmitt, B. 1998. D $\alpha 3$, a new functional $\alpha$ subunit of nicotinic acetylcholine receptors from Drosophila. J. Neurochem. 71: 853-862.

Seeburg, P.H. 2002. A-to-I editing: New and old sites, functions and speculations. Neuron 35: 17-20.

Shimomura, M., Okuda, H., Matsuda, K., Komai, K., Akamatsu, M., and Sattelle, D.B. 2002. Effects of mutations of a glutamine residue in loop $\mathrm{D}$ of the $\alpha 7$ nicotinic acetylcholine receptor on agonist profiles for neonicotinoid insecticides and related ligands. Br. J. Pharmacol. 137: $162-169$.

Shimomura, M., Yokota, M., Okumura, M., Matsuda, K., Akamatsu, M., Sattelle, D.B., and Komai, K. 2003. Combinatorial mutations in loops $\mathrm{D}$ and $\mathrm{F}$ strongly influence responses of the $\alpha 7$ nicotinic acetylcholine receptor to imidacloprid. Brain Res. 991: 71-77.

Shimomura, M., Yokota, M., Matsuda, K., Sattelle, D.B., and Komai, K. 2004. Roles of loop C and the loop B-C interval of the nicotinic receptor $\alpha$ subunit in its selective interactions with imidacloprid in insects. Neurosci. Lett. 363: 195-198.

Smit, A.B., Brejc, K., Syed, N., and Sixma, T.K. 2003. Structure and function of AChBP, homologue of the ligand-binding domain of the nicotinic acetylcholine receptor. Ann. N. Y. Acad. Sci. 998: 81-92.

Suchail, S., Debrauwer, L., and Belzunces, L.P. 2004. Metabolism of imidacloprid in Apis mellifera. Pest Manag. Sci. 60: 291-296.

Thany, S.H. and Gauthier, M. 2005. Nicotine injected into the antennal lobes induces a rapid modulation of sucrose threshold and improves short-term memory in the honeybee Apis mellifera. Brain Res. 1039: 216-219.

Thany, S.H., Lenaers, G., Crozatier, M., Armengaud, C., and Gauthier, M. 2003. Identification and localization of the nicotinic acetylcholine receptor $\alpha 3$ mRNA in the brain of the honeybee, Apis mellifera. Insect Mol. Biol. 12: 255-262.

Thany, S.H., Crozatier, M., Raymond-Delpech, V., Gauthier, M., and Lenaers, G. 2005. Apis $\alpha 2$, Apis $\alpha$ 7-1 and Apis $\alpha$ 7-2: Three new neuronal nicotinic acetylcholine receptor $\alpha$-subunits in the honeybee brain. Gene 344: 125-132.

Thompson, J.D., Gibson, T.J., Plewniak, F., Jeanmougin, F., and Higgins, D.G. 1997. The CLUSTAL_X windows interface: Flexible strategies for multiple sequence alignment aided by quality analysis tools. Nucleic Acids Res. 25: 4876-4882.

Tomizawa, M. and Casida, J.E. 2005. Neonicotinoid insecticide toxicology: Mechanisms of selective action. Annu. Rev. Pharmacol. Toxicol. 45: 247-268.

Unwin, N. 2005. Refined structure of the nicotinic acetylcholine receptor at 4A resolution. J. Mol. Biol. 346: 967-989.

Winston, M.L. 1987. Development and nutrition. In The biology of the honeybee, pp. 46-71. Harvard University Press, Boston, MA.

Wustenberg, D.G. and Grunewald, B. 2004. Pharmacology of the neuronal nicotinic acetylcholine receptor of cultured Kenyon cells of the honeybee, Apis mellifera. J. Comp. Physiol. A Neuroethol. Sens. Neural. Behav. Physiol. 190: 807-821.

Received August 10, 2005; accepted in revised form November 14, 2005.

\section{Genome Research}

www.genome.org 


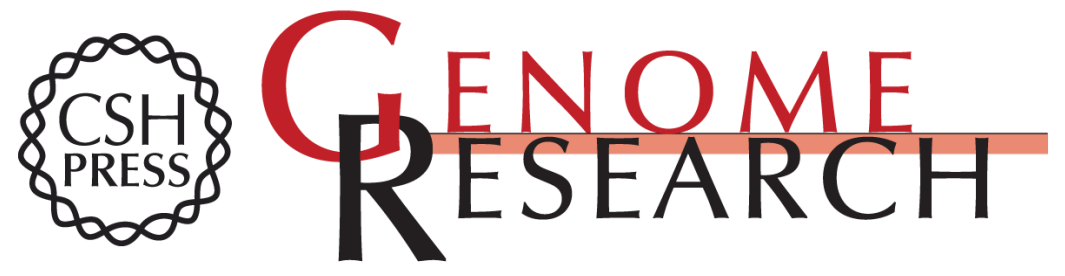

\section{The nicotinic acetylcholine receptor gene family of the honey bee, Apis mellifera}

Andrew K. Jones, Valerie Raymond-Delpech, Steeve H. Thany, et al.

Genome Res. 2006 16: 1422-1430 originally published online October 25, 2006

Access the most recent version at doi:10.1101/gr.4549206

Supplemental http://genome.cshlp.org/content/suppl/2006/11/01/gr.4549206.DC1

Material

References This article cites 67 articles, 7 of which can be accessed free at: http://genome.cshlp.org/content/16/11/1422.full.html\#ref-list-1

Open Access Freely available online through the Genome Research Open Access option.

License Freely available online through the Genome Research Open Access option.

Email Alerting Receive free email alerts when new articles cite this article - sign up in the box at the Service top right corner of the article or click here.

\section{Affordable, Accurate Sequencing.}

